\title{
Perceived inhibitors to rural practice among physiotherapy students
}

\section{- Reg Mitchell}

There is not a considerable body of literature on the need for allied health professionals in rural practice. Much of the relevant literature is principally in the form of unpublished reports and manpower studies conducted by various professional organisations. Consequently, it is not in the public domain.

In rural communities, allied health professionals may provide the sole source of patient management, or their services may be complementary to that of other health professionals including medical practitioners. Their professional decision making is autonomous and they are legally accountable for their actions.

Very little work has been done to determine the characteristics of undergraduate students in health disciplines which make them more or less likely to enter rural practice. Australian and American studies of medical students indicate that students from a rural background are more likely to return to rural practice than are students who originate in the cities (Kamien and Buttfield 1990, Knopke et al 1986, Rabinowitz 1988).

Piterman and Silagy (1991) examined the attitudes of junior hospital doctors towards rural training and practice in Victoria. This study found that these respondents from a rural background were more likely to express an intention

This descriptive study was undertaken to determine perceptions of undergraduate physiotherapy students which would make them more or less likely to enter rural practice. A total of 607 self-administered questionnaires were distributed to undergraduates in The University of Sydney and 546 completed documents were returned. Students perceived the major inhibitors as social (isolation from family, friends and partner) and recreational (lack of theatre, entertainment, etc). Influences which would attract graduates to rural practice were lifestyle (relaxed, less stressful, healthier), lower cost of living, seeing more of Australia and professional autonomy. Knowledge of these perceptions will enable educators, the profession and potential employers to develop and implement strategies that will negate the negative and re-enforce the positive perceptions.

(Mitchell RA: Perceived inhibitors to rural practice among physiotherapy students. Australian Journal of Physiotherapy 42:47-52)

Key words: Career Choice; Rural Health; Social Environment; Students, health occupations

RA Mitchell MSc, MEd, PhD is a senior lecturer in the Department of Behavioural Sciences, Faculty of Health Sciences, The University of Sydney.

Correspondence: Dr Reg A Mitchell, Department of Behavioural Sciences, Faculty of Health Sciences, The University of Sydney, PO Box 170, Lidcombe NSW 2141.

This project was funded by the NSW Department of Health, Housing and Community

Services Rural Health Support Education and Training Program (RHSET).

The SA Journal of Physiotherapy gratefully acknowledges the Australian Journal of Physiotherapy for permission to publish this article. to train and practice in the country. The most important determinants in choosing a rural training post were found to be perceived quality of education/training facilities and the view of the practitioners' partners or spouses.

The shortage in Australia of doctors in rural practice is also addressed by Silagy and Piterman (1991). These authors reported that 87 per cent of their respondents expressed a desire to do their internships and postgraduate training in a metropolitan hospital. A strong relationship was observed between a student's rural background and the student's subsequent intention to train and work in a rural area.

Hanson et al (1990), in a study of 167 nurses in rural practice in the United States of America, found that demographic factors (age, education, salary, marital status and number of dependents) were not strong predictors of retention in rural practice. Nursing autonomy was the most effective predictor of intention to remain in their current positions. Health professionals working in rural areas face handicaps like distance, deficient support services, professional isolation and lack of continuing education opportunities (Hanson et al 1990).

A shortage of medical practitioners entering rural practice has also been reported in New Zealand (Barnett 1991). This author reports a declining availability of general practitioners in rural areas over a 16 year period. A similar trend is also reported in studies conducted in the USA (Kirk 1991).

Hodgson (1991) identified issues in rural health practice such as the need for more staff, better career and support structures, greater team work, development of specific resources, recognition of different modes of service delivery and the need for greater awareness of the profession outside urban centres. McAllister et al (1992) and Craig and Mudge (1989) suggest that the shortage of rural health practitioners may be due to the urbanisation of undergraduate health science programs and the predominance of students from urban centres in these programs.

The purpose of this report is to present the findings of a study which attempted to identify perceived reasons which would or would not attract graduates in physiotherapy to rural practice. The study also examined changes in these reasons as students progressed through their course from the first to the final year.

\section{Method}

During the period October 1992 to June 1994, a total of 607 self administered questionnaires were distributed to undergraduate students in physiotherapy schools. Items in this instrument included student identification number (to facilitate follow up of students) and information about both semester and permanent home postcodes (to facilitate identification of students whose permanent residence was in a rural location). In keeping with University ethical require- 
ments, participation was voluntary and a guarantee of anonymity was given and maintained.

Included in the questionnaire were lists of reasons for and against entering rural practice. These lists were generated using a pilot group of 35 final year physiotherapy students and five senior instructors in the faculty, asking them to respond to two open ended statements, viz: "Give five reasons why you would not enter rural practice on graduating", and "Give five reasons why you would enter rural practice on graduating". All reasons generated from this process were incorporated into the final questionnaire.

On the final protocol subjects were requested to respond to "In your case which of the following would be reasons for you not entering rural practice on graduation? (You may tick more than one.)". A total of 19 specific reasons plus "Other" comprised the list of inhibitors (see Table 1). Each respondent's total number of reasons for not entering rural practice was obtained. It was assumed that the higher this score, the less predisposed the respondent would be to enter rural practice.

\begin{tabular}{|l|c|c|c|c|c|}
\hline \hline \multirow{2}{*}{ Table 1. Reasons for not entering rural practice, percentage by year } \\
\hline \multicolumn{1}{|c|}{ REASON } & \multicolumn{5}{c|}{ YEAR } \\
\cline { 2 - 7 } & 1 & 2 & 3 & 4 & TOTAL \\
\hline Away from family/friends & 57.7 & 58.6 & 67.6 & 73 & 63.4 \\
\hline Family house in city & 35.6 & 44.8 & 51.4 & 50 & 43.6 \\
\hline Varied employment in city & 37.5 & 41.4 & 40.5 & 37.8 & 38.8 \\
\hline Long distances to travel & 36.5 & 29.3 & 37.8 & 33.8 & 34.4 \\
\hline No night-life in the country & 26.9 & 31 & 40.5 & 39.2 & 33 \\
\hline Lack of entertainment & 28.8 & 29.3 & 27 & 33.8 & 30 \\
\hline Lack of professional contact & 25 & 34.5 & 27 & 29.7 & 28.6 \\
\hline Do nol know anyone in the country & 28.8 & 36.2 & 29.7 & 25.7 & 29.7 \\
\hline Counlry life "loo slow" & 17.3 & 15.5 & 24.3 & 31.1 & 21.6 \\
\hline $\begin{array}{l}\text { Experience in city hospitals more } \\
\text { highly regarded }\end{array}$ & 20.2 & 20.7 & 18.9 & 20.3 & 20.1 \\
\hline Uprooting family/spouse & 13.5 & 17.2 & 21.6 & 25.7 & 18.7 \\
\hline Boyfriend/girlfriend works in the city & 15.4 & 20.7 & 16.2 & 18.9 & 18.7 \\
\hline $\begin{array}{l}\text { Connot keep pace with professional de- } \\
\text { velopment }\end{array}$ & 13.5 & 20.7 & 16.2 & 16.2 & 16.1 \\
\hline Rural hospitals/clinics poorly equipped & 12.5 & 17.2 & 16.2 & 17.6 & 15.4 \\
\hline Lack of jobs in country & 18.3 & 10.3 & 8.1 & 8.1 & 12.5 \\
\hline Litlle promotion opportunity in country & 7.7 & 6.9 & 10.8 & 13.5 & 9.5 \\
\hline Higher cost of living & 4.8 & 6.9 & 10.8 & 16.2 & 9.2 \\
\hline Rural community "small minded" & 8.7 & 6.9 & 8.1 & 9.5 & 8.4 \\
\hline Other & 2.9 & 0.0 & 2.7 & 1.4 & 1.8 \\
\hline Too much responsibility in country & 1.9 & 0.0 & 0.0 & 0.0 & 0.7 \\
\hline Percentage of respondents & 38.1 & 21.2 & 13.6 & 27.1 & \\
\hline
\end{tabular}

Subjects were also asked to respond to "In your case, which of the following would be reasons for your entering rural practice after graduating? (You may tick more than one.)" There were 16 reasons plus "Other" to which the students might respond (see Table 2). A total score for each individual on this variable was generated by summing the individual reasons for entering rural practice. This score was interpreted as a high score, indicating a positive attitude and predisposition to entering rural practice.

On return of the completed instruments, data were coded and entered into a Personal Computer in 80 column format. All analyses of the data were carried out using the
Statistical Package for the Social Sciences (SPSS) PC software. Responses to each of the for and against items were coded as " 0 " for not identified and " 1 " if identified by the student. Reasons for and against rural practice for the total sample and by year were computed for each item. Using SPSS PC+ total scores for reasons for and against were computed by year and for the entire sample.

Using the $t$ test statistic (in SPSS PC+), comparisons were made between urban and rural sourced students on their total mean scores for and against entering rural practice. The chi-square test was used to compare responses across years on each of the individual for and against items.

Table 2. Reasons for entering rural practice, percentage by year

\begin{tabular}{|l|c|c|c|c|c||}
\hline \multirow{2}{*}{ REASON } & \multicolumn{5}{c|}{ YEAR } \\
\cline { 2 - 6 } & 1 & 2 & 3 & 4 & TOTAL \\
\hline Relaxed lifestyle & 70.2 & 65.5 & 64.9 & 59.4 & 66 \\
\hline Healthier lifestyle & 52.9 & 56.9 & 70.3 & 66.2 & 60.1 \\
\hline No polluted air & 57.7 & 60.3 & 64.9 & 58.1 & 69.7 \\
\hline See a bit more of Australia & 54.8 & 51.7 & 54.1 & 59.5 & 55.7 \\
\hline Get away from city stresses & 56.7 & 48.3 & 48.6 & 54.1 & 53.5 \\
\hline Professional independence & 35.6 & 44.8 & 43.2 & 36.5 & 39.2 \\
\hline Cheaper rent/housing & 36.5 & 44.8 & 40.5 & 29.7 & 37.4 \\
\hline Like small lowns & 30.8 & 41.4 & 35.1 & 33.8 & 34.8 \\
\hline More oble to save money & 31.7 & 25.9 & 29.7 & 36.5 & 31.9 \\
\hline Member of a close communily & 26 & 27.6 & 27 & 32.4 & 28.6 \\
\hline No jobs in city & 26.9 & 27.6 & 18.9 & 21.6 & 24.9 \\
\hline More respected member of community & 15.4 & 15.5 & 18.9 & 21.6 & 18 \\
\hline Family lives in the country & 22.1 & 27.6 & 10.8 & 0.0 & 16.2 \\
\hline Life more adventurous & 17.3 & 8.6 & 13.5 & 20.3 & 16.2 \\
\hline Can "live off land" & 14.4 & 17.2 & 13.5 & 16.2 & 15.8 \\
\hline Beller pay & 15.4 & 17.2 & 18.9 & 8.1 & 14.7 \\
\hline Other & 7.7 & 13.8 & 13.5 & 12.2 & 11.4 \\
\hline \hline
\end{tabular}

\section{Results}

A total of 607 questionnaires were distributed to physiotherapy students through the Behavioural Science seminar groups. A total of 546 (90 per cent) completed questionnaires were returned. Of the completed surveys, 322 (59.0 per cent) were from students who originated in the city and 224 (41.0 per cent) from the country.

\section{Table 3. Signilicant reasons across years for not entering rural proctice}

\begin{tabular}{|l|c|}
\hline \multicolumn{1}{|c|}{ REASON } & CHI-SQUARE VALUE \\
\hline Away from family/friends & $10.45^{*}$ \\
\hline Family house in city & $9.78^{*}$ \\
\hline No night life in couniry & $8.14^{*}$ \\
\hline Country life "too slow" & $12.97^{* *}$ \\
\hline Uprooling lamily/spouse & $9.07^{*}$ \\
\hline Lack of jobs in the country & $10.77^{*}$ \\
\hline Higher cost of living & $14.55^{* *}$ \\
\hline${ }^{*} \mathrm{p}<0.05^{* *} \mathrm{p}<0.01$ & \\
\hline
\end{tabular}

The percentages for each of the individual reasons, by year, for not entering rural practice is given in Table 1 . The percentages of students selecting each reason for entering rural practice are given in Table 2 . The reasons given in Tables 1 and 2 are presented in rank order from most to 
least frequently selected by the total number of respondents.

A chi-square analysis was carried out on the response by year to each statement, in Table 1 and Table 2. Reasons for not entering rural practice which yielded significant chisquare values are given in Table 3 . Only one reason for entering rural practice, i.e. "family lives in the country", yielded a significant chi-square value, $\left(X_{(3)}^{2}=\right.$ $39.08, p<0.001$ ).

Finally, comparisons between urban and rural sourced students on their mean scores for and against entering rural practice were analysed using student $t$ tests. There was a significant difference $\left(t_{(544)}=8.97, p<0.001\right)$ on the reasons against rural practice. Rural-sourced students had a significantly lower mean $(x=3.4, \mathrm{SD}=1.95)$ number of reasons for not entering rural practice than their urban-sourced

peers $(\bar{x}=5.3, \mathrm{SD}=2.81)$. While the source of the student does not appear to differentiate students on reasons for entering rural practice, those with a rural background identified fewer reasons against entering rural practice.

\section{Discussion}

Three of the top 10 ranked inhibitors (Table 1) related to social factors: away from family and friends; family house is in the city; and does not know anyone in the country. There is little than can be done to replace family and friends. However, consideration might be given to providing the new graduate entering rural practice with some form of social support. A variety of measures might be adopted, for example a local resident/health professional could be designated $a$ "buddy" to help in the new graduate's integration into their new community. The buddy system might also reduce the anxiety associated with separation from family and friends. Members of the local community might "adopt" the new graduate or a regional physiotherapist might have, as part of their duties, responsibility for ensuring the welfare of newly arrived graduates.

There were three profession-related reasons for not entering rural practice ranked in the top 10 inhibitors. These reasons were: varied employment in the city; lack of professional contact in the country; and experience in a city hospital more highly regarded.

Upon graduation, students may wish to focus their professional career on a particular speciality rather than work in a situation with more diverse calls on their skills. Speciality physiotherapy units are extremely rare in rural institutions. Another possible interpretation of this response might be that the students perceived that rural institutions, being relatively small, offer a limited range of clinical areas in which to work and therein consolidate their newly acquired skills. In large city institutions, students may believe that a new graduate is able to be rotated through a large number of diverse clinical specialties, thereby consolidating their clinical skills.

Although there is no internship for the new physiotherapy graduate, it is considered by many in the profession that these graduates still require exposure to and practice in a wide variety of clinical areas. It is common practice in some large city hospitals to rotate the new graduate around a range of clinical areas. If the new graduate is to be attracted to rural practice, then undergraduate students need to be informed that there is a continuation of this in-service training in rural and urban placements. Exposure to a total range of clinical areas for these graduates may be facilitated by exchanging the new graduate practising in a rural area with a new graduate practising in a large city hospital where the opportunity to rotate through a variety of clinical specialities is available. Such a practice would expose both groups of new graduates to rural and urban practice.

The perception of undergraduate students that the more varied employment available in the city would be advantageous may not necessarily be related to their need to be exposed to a variety of clinical settings as early practitioners. Some may seek to specialise quite early in their careers and believe that opportunities to specialise are limited in rural institutions

Lack of professional contact, ranked seventh, was perceived to be an inhibitor to rural practice. Certainly, a physiotherapist entering practice in a small rural community may well be the sole practitioner in that community. If this is the situation, there needs to be established and maintained a means whereby these practitioners are not professionally isolated. A variety of strategies might be employed to overcome this professional isolation. These strategies might include regular visits by a regional coordinator. Consideration might also be given to establishing an electronic facility such as Email, thereby enabling the practitioner to maintain professional contact and obtain professional support. Employing authorities, governments and professional associations should facilitate rural practitioners' attendance at professional conferences and workshops. Rural practitioners might be provided with access to professional journals through a circulating mail library. lssues related to rural practice might also be considered at designated sessions at professional conferences. Similarly, rural practice issues might constitute either a regular section or a special issue of professional journals.

That experience in a city hospital is more highly regarded in the profession may well be an incorrect perception among undergraduates. The near and new graduate physiotherapist needs to be assured that rural practice is of professional value and equal to urban practice. This assurance would normally be given by both training institutions and employing authorities. It is possible that responses to this inhibitor were related to their perception of the limited range of clinical specialities available in some rural towns.

While long distance (ranked fifth in Table 1) is certainly true in centres remote from the coastal fringe, the availability of adequate public transport between towns, regional centres, and the large cities needs to be assessed and promoted to potential rural practitioners. Where a new graduate accepts a position in a town remote from the family home, consideration might be given to supporting the graduate, especially in the early years, with some means of inexpensive communication with home and perhaps subsidising an annual trip to the family home.

The other perceived major inhibitors to rural practice relate to recreational activities, lack of entertainment, and 
country life being "too slow". If new graduates are to be attracted to rural practice there is a need to promote the special and unique recreational activities that are available in a rural community. These activities might be promoted to final year students as benefits associated with entering rural practice and may thus contribute to attracting more new graduates to such practice.

Differences across the years on reasons for not entering rural practice (Table 3 ) were obtained for seven of the 20 reasons listed in Table 1 . Three of these reasons (uprooting family/spouse, lack of jobs in country, and higher cost of living) were not ranked in the top 10 reasons against rural practice and are not considered to be differential inhibitors. Of the other four reasons, final year students gave the highest percentage and third year students the next highest percentage of yes responses to "away from family and friends" and "country life too slow". For the inhibitors "family house in city" and "no night life in country", third year students gave the highest percentage and final year students the next highest percentage of yes responses. It appears that for third or fourth year students, these particular inhibitors do differentiate them from students in more junior years

The lifestyle offered in a rural community predominated in the top 10 reasons for entering rural practice. The top five ranked reasons for entering rural practice were: relaxed lifestyle; healthier lifestyle; no pollution; see more of Australia; and less stressful. These positive attributes of rural practice could be employed to promote rural practice to intending graduates. Those wishing to promote and attract students to rural practice should take advantage of these perceived attributes of rural practice.

Students also perceived that the cost of living in the country is cheaper than in the city, and that they would be better able to save money and obtain cheaper housing/rental accommodation in the country. However, the general cost of living in a country town can be considerably higher than in the city.

Other positive attributes of rural life ranked by the students were that they perceived community structures as being positive attributes of rural practice. They stated that they liked small towns, and that they liked to be members of a close community.

The only profession-related reason for entering rural practice was the perception of professional autonomy in rural practice. This parallels a similar findings among nurses in the USA (Hanson et al 1990).

Comparisons across years in the top 10 ranked reasons indicated no differences in the proportions choosing reasons for entering rural practice.

It must be noted that the majority of respondents ( 38.1 per cent) were first year students who would have had only minimal exposure to clinical practice in general, let alone a rural practicum. These students' perceptions of either rural or urban clinical practice may have been based on their own preconceptions and biases or on culturally communicated impressions and biases from their peers, students in higher years, or staff. What must be questioned is the validity of their responses to many of the questions asked. However naive the attitudes of first year students may be, if we are to actively promote rural practice in our training programs, the perceived positive attributes of rural practice should be reinforced as early as possible in the curriculum. Early identification of the perceived negative attributes of rural practice will allow teachers and curriculum designers to counter such attitudes.

This paper does not address the specific content in the physiotherapy curriculum that may be influential in shaping students' attitudes and perceptions towards rural practice during their four-year course. It is highly likely that such content, the specific nature of any clinical practicum and personalities of teachers and clinical supervisors will all have considerable influence on a student's attitudes to rural or urban practice. Further research on the effects of curriculum and instructors in influencing students' perceptions of rural practice is considered to be highly worthwhile. Instructors should be aware of the extent to which they and the material taught influences their students.

It must also be noted that any quality curriculum is an evolving entity and that the curriculum and instructors will vary with time. Thus, for example, second year students in 1993 might have had slightly different material taught by different instructors than that presented to second year students in 1992 or 1994 . This source of variability, albeit small, must be acknowledged as a further source of error in the present study. The students' perceptions of practice will be influenced cumulatively as they proceed through their course. Differential influences in the course will, of necessity, yield differential perceptions.

Students' perceptions of factors that would influence their selection of practice will be premised on inexperience. Even final year students have not entered the workforce and the students' perceptions are likely to reflect neither the realities of the workplace nor the attitudes of urban or rural practitioners. A potential follow-up to the present study might be to examine the perceptions of practitioners toward rural practice and compare these attitudes with the students' perceptions. Another related project might be to assess the impact of clinical supervisors and clinical placements on students' perceptions of rural practice.

The reasons given in Tables 1 and 2 were generated from a sample of fourth year students. It must be recognised that had these reasons been generated from students in other years, then a number of different reasons might have emerged. However, the lists in these two tables were not generated entirely from the student base. Student responses were supplemented by material from senior staff within the Faculty and School. Reasons identified by instructors may not necessarily be those identified by, or pertinent to, students.

The extent to which the perceptions discussed in this study do in reality influence students entering rural or urban practice could well be examined in a further study. New and recent graduates could be sampled and studied as to the extent to which their perceptions as students influenced their choice of practice. Clearly, those wishing to attract new graduates to rural practice should accentuate and promote the positive attributes of rural practice. The negative aspects of rural practice, as perceived by undergraduates and identified in this study, can be addressed 
and, if not entirely eliminated, promotionally offset by the advantages.

Further research should also be undertaken to examine the extent to which the positive/negative perceptions of undergraduate students become offset by the advantages/disadvantages of rural practice. In other words, to what extent do these perceptions influence the reality?

\section{Conclusion}

In summary, the major perceived inhibitors (ranked in the top 10) to undergraduates seeking positions in rural practice were social (away from families and friends; family lives in city; do not know anyone in country), physical (long distances to travel), recreational (no night life in the country; lack of entertainment; country life too slow), and professional (varied employment in city; lack of professional contact; experience in city more highly regarded). In contrast, the top 10 reasons for entering rural practice could be generally described as being related to lifestyle.

This descriptive study suggests that further research is needed to determine reasons why graduates do and do not enter rural practice, whether undergraduate perceptions outweigh the realities of professional practice, and the critical roles played by those who may be described as "significant others" during the students' undergraduate training.

Whether the students' perceptions do or do not reflect the realities of rural practice those wishing to attract the new graduate to rural practice need to be aware of the perceived positive and negative characteristics held by students. This knowledge will enable practices to be developed and implemented which will negate the negative perceptions and accentuate the positive perceptions.

\section{References}

Darnett JR (1991): Where have all the doctors gone? Changes in the geographic distribution of general practitioners in New Zealand since [975. 1: Regional and urban-rural differences. Now Zcaland Medical louma/ 104:314-316.

Craig $M$ and Mudge $P$ (1989): Training for rural practice - still in the too hard basket? Brisbane: University of Queensland.

Hanson CM, Jenkins AS and Ryan RC (1990): Factors related to job satisfaction and autonomy as correlates of potential job retention for rural nurses. Journal of rural health 6:302-316.

Hodyson L (1991): Report to the membership of the Australian Association of Speech and Hearing on the National Rural Health Conference. Australian Communications Quarterly 2:8-9.

Kamien M and Buttfield IH (1990): Some solutions to the shortage of general practitioners in rural Australia. Mcdical Journal of Australia 153:105-107.

Kirk K (1991): Rural areas losing appeal for young doctors. Ohio Medicine 87:24-27.

Knopke HI, Northrup RS and Hartman JA (1986): BioPrep. A premedical program for rural high school students. Journal of the Amcrican Medical Association 256:2548-2451.

McAllister L, Eadie P and Hays R (1992): Promoting rural carcers. Unpublished manuscript.

Piterman L and Silagy C (1991): Hospital interns' and residents' perceptions of rural training and practice in Victoria. Medical Journal of Australia 155:630-633.

Rabinowitz HK (1988): Relationship between US medical school admission policy and graduates entering family practice. Family Practice 5:142-144.

Silagy C and Piterman (1991): The attitudes of senior medical students from two Australian schools towards rural training and practice. Acadc'my of Medicine 66:417-419.

\section{FUNCTIONAL CAPACITY EVALUATION}

The Basic Blankenship Courses 1997

Comprehensive 31/2-day course (28 hours). Instructor: Yvonne Strydom, Physiotherapist
Wellington NZ:
06 - 09 February
Cairns Aust:
20 - 23 February

Perth Aust:

06 - 09 March

DURBAN S Africa:

24 - 27 April 1997

Fee: Aus $\$ 1175.00$ includes: Training, Manual, 5 Test Books, cont bfasts, am/pm teas, lunch.

Closing dates: 4 weeks prior to start, unless filled sooner.

This Seminar is the ideal FCE training course for those Practitioners who want to start performing quality FCE's with a minimum of capital expenditure. You will learn how to do a manual whole body FCE, document the entire process in a Test Booklet, and draw in all the information to compile the FCE Form.

This FCE has been accepted by State, Federal and 3rd Party payers for its scope of uses, as well as its Validity throughout USA, Australia, NZ and UK.

You can use this Functional Capacity Evaluation for planning a Patient's Semi-Acute Rehabilitation, their Return to Work, or for Medico-Legal purposes.

For further information/Registration form, contact:

Yvonne Strydom Telephone \#61 732833721 Fax\#61 738832367 